\title{
La ópera como herramienta de acción social y unión comunitaria. Reflexiones acerca del proceso creativo, montaje y estreno de La Malén
}

\author{
por \\ René Silva Ponce \\ Universidad Alberto Hurtado, Chile \\ resilva@uahurtado.cl \\ Pontificia Universidad Católica de Chile, Chile \\ resilvap@uc.cl
}

Tengo una historia profesional dividida entre la docencia y la composición musical. La docencia llegó primero a mi vida, estudié pedagogía en música y una vez titulado trabajé en colegios y orquestas juveniles. Mientras trabajaba, estudié la carrera de Licenciatura en composición, lo que abrió las puertas a mi segundo camino. Actualmente sigo ejerciendo la docencia, pero a estudiantes universitarios, instancia que me alegra muchísimo, ya que trabajo en la formación de nuevos profesores de música. Con ello trato de aportar nuevas ideas desde la mirada de este compositor-docente al que le es difícil dividir o hacer-pensar por separado. Ambos caminos funcionan en conjunto en mi vida. Sin embargo, nunca había trabajado en un proyecto que uniera ambas líneas, hasta que recibí el maravilloso encargo de escribir una ópera para niños, que sería, además, tocada y cantada por niños y niñas.

Con gran nostalgia a fines de 2017 decidí dejar el proyecto de la Orquesta Sinfónica Municipal de Paine, en donde trabajé por once años. Mis actuales compromisos académicos y composicionales ya no permitían hacerme cargo de este trabajo. No obstante, mi mayor satisfacción al dejar ese proyecto fue haber podido hacer un relevo generacional con algunos de los alumnos con que se había iniciado la orquesta. Ellos son ahora quienes siguen a cargo del proyecto comunal, formando a las nuevas generaciones de músicos paininos. Un grupo de jóvenes que tuvo la posibilidad de conocer la música en un momento de sus vidas, camino que luego eligieron para sus estudios profesionales y que ahora, también, se presenta como una fuente laboral.

Mi experiencia trabajando en Paine me permitió apreciar de cerca cómo la música se convierte en una herramienta de cambio social no solo a nivel individual, sino también a nivel familiar y comunitario. Recuerdo cuando hace algunos años un apoderado se acercó, luego de un concierto, para contarme cómo la música había cambiado sus vidas. A este apoderado, el que se autodefinía como futbolero $^{1}$, le había sorprendido enormemente que su hijo le hubiese pedido como regalo de cumpleaños una entrada para el Teatro Municipal. Con los años, este joven decidió estudiar la carrera de Interpretación musical. Hace unas semanas, antes de terminar este escrito, me encontré con este joven en un concierto, venía llegando de un festival en Alemania y se prepara para audicionar y continuar sus estudios en Europa. Esta situación me permitió reafirmar aún más que la música puede generar verdaderos cambios en la vida de las personas.

${ }^{1}$ Denominación que se utiliza en Chile para nombrar a un fanático del fútbol. 
Podría seguir escribiendo muchas líneas acerca de mi experiencia como director de orquestas infantiles, pero bosquejo estas ideas solo a modo de introducción para explicar por qué no tuve ninguna duda en aceptar la propuesta de escribir una ópera para niños para la comuna de Panguipulli. Sabía que ese proyecto también dejaría una huella imborrable en las vidas de esos niños y sus familias. A pesar de la certeza, me fui sorprendiendo cada vez más en el camino. A continuación, trataré de dar parte de ese testimonio.

\section{EL ENCARGO}

Conocí al maestro Rodolfo Fischer en 2017 cuando fuimos colegas en un Diplomado en Dirección Orquestal de la Universidad Alberto Hurtado. No tuvimos mucho tiempo de compartir durante el desarrollo del curso, debido a que nuestras clases se realizaban en periodos diferentes, pero antes de su retorno a Suiza alcancé a entregarle algunas de mis partituras orquestales. Fue una grata sorpresa cuando recibí su llamado un sábado de abril para tomarnos un café y hablar de un proyecto. Para mí era totalmente alentador que un director de su categoría me citara a tomar un café y hablar de proyectos. Sospeché que se trataba de alguna de las obras que le había entregado el año anterior, pero jamás me hubiese imaginado que ese llamado terminaría en la composición de mi primera ópera.

Luego de conversar un rato, me contó de la interesante actividad artística que se venía realizando en la comuna de Panguipulli y que, además, estaba colaborando con Alexander Sepúlveda, uno de sus alumnos avanzados de dirección orquestal y director titular de la orquesta infantil y juvenil de la comuna. Casualmente nos conocíamos con Alexander luego de haber sido compañeros en algunos cursos de dirección orquestal en la Fundación de Orquestas Juveniles e Infantiles de Chile hace varios años. Yo no entendía muy bien hacia dónde iba la conversación, ya que no llegábamos al punto de las obras orquestales que le había entregado el año anterior. En medio de la conversación se detuvo y me dijo sin mayor preámbulo: "te queremos encargar una ópera".

Por un lado, hubo ciertos asuntos estilísticos que llevaron al maestro Fischer a pensar en mí para el encargo. Gran parte de mi música tiene relación con el universo sonoro chileno, en especial de los pueblos originarios y el imaginario mapuche. Por otro lado, mi trabajo como docente fue un factor trascendental. Yo me formé como profesor de música antes de estudiar la carrera de composición y, como mencionaba en la introducción de este escrito, tuve durante largo tiempo una estrecha relación con el mundo de las orquestas juveniles e infantiles. Así que conozco bastante bien lo que puede y no puede hacer un niño o niña con un determinado tiempo de estudio en su instrumento.

De esta forma me uní al proyecto Cenicienta, Magia y Leyenda, para el que se encontraban trabajando con el cuento musicado de La Cenicienta de Pedro Humberto Allende, escrito en 1948. Querían complementar el programa con una historia local equivalente a la historia de Cenicienta. Ese mismo día llamé al poeta mapuche Elicura Chihuailaf, mi amigo, para pedirle recomendaciones de algún cuento o leyenda de la zona que se pareciera a Cenicienta o que en su defecto tuviera alguna princesa como protagonista. Nos recomendó la historia de la Kalfü-malén, princesa azul que habita los bosques y que canta respecto del amor. El personaje era interesante considerando que buscábamos una historia para una ópera, pero había que indagar en una historia con más similitudes a Cenicienta. Finalmente, no utilizamos la historia de la Kalfü-malén, pero este fue el punto de partida para llegar a otra historia local conocida como La niña calavera. Este cuento relata la historia de Malén, hija de un lonco y que vive con su madrastra y hermanastra. Ellas le encargan a una $k a l k u^{2}$ un hechizo para convertir la cara de la niña en calavera. Para romper el hechizo, Malén debe encontrar todos los huesos de un guerrero. Con el fin de lograrlo debe internarse en el bosque y ahí enfrentar sus miedos y sombras.

Una de mis grandes aprehensiones al momento de aceptar el encargo era el tiempo acotado que tenía para escribir una obra de 30 a 40 minutos. Tres meses era el plazo, por lo que cada día que pasaba significaban valiosas horas de trabajo. Había que gestionar rápidamente el argumento y libreto de la ópera, asunto que asumió finalmente el actor Felipe Castro Fones, director general del proyecto y que solo en un par de semanas tuvo la versión final para que yo iniciara el proceso de composición musical. Y por mi parte, necesitaba de un copista, ya que escribo toda mi música a mano. Rodolfo

2 En la cultura mapuche, kalku es un brujo o bruja que invoca y trabaja con espíritus malignos para provocar daño a otras personas o seres (N. del E.). 
Fischer decidió asumir la delicada labor de digitalización de la partitura, quedando así conformado el equipo creativo de la ópera La Malén.

\section{LAS ORQUESTAS JUVENILES E INFANTILES Y SU LABOR SOCIAL}

Las orquestas infantiles y juveniles juegan un importante rol en la formación musical de niños y jóvenes. Algunos autores han investigado acerca de sus beneficios y proponen que la participación en este tipo de agrupaciones mejora el rendimiento escolar ${ }^{3}$. Otros investigadores han analizado los efectos que produce a nivel social para los niños, proponiendo que la participación de una orquesta los hace integrarse y sentirse parte de una sociedad de la que antes se sentían marginados ${ }^{4}$. En lo personal, luego de once años de arduo trabajo en proyectos de orquestas infantiles y juveniles, puedo dar testimonio de estos beneficios y que independientemente si un joven decide dedicarse o no a la música, el haber pasado por una orquesta deja una huella imborrable en su vida y la de sus familias. Esta apreciación personal tiene relación con la proyección del Sistema Nacional de Orquestas y Coros Juveniles e Infantiles de Venezuela, el que no considera como objetivo principal formar músicos profesionales, sino fomentar el desarrollo de miembros alegres y colaborativos de una sociedad ${ }^{5}$. En correlación con esta propuesta, José Antonio Abreu, fundador del proyecto de orquestas en Venezuela, propuso que "la orquesta y el coro son mucho más que estructuras artísticas: son ejemplos y escuelas de la vida cívica"6.

Pero en Chile el movimiento de orquestas juveniles e infantiles nace mucho antes que en Venezuela gracias al importante trabajo de Jorge Peña Hen en la ciudad de La Serena ${ }^{7}$. La Sociedad Juan Sebastián Bach $^{8}$, agrupación fundada por Peña Hen, había logrado importantes avances en materias musicales en la zona norte de Chile, como la creación de la Orquesta de Cámara de la Sociedad J. S. Bach en 1953 y la Orquesta Filarmónica de La Serena en 1959. Sin embargo, lamentablemente, en 1963 estos proyectos fueron afectados por la disminución de aportes fiscales, lo que trajo como consecuencia la disolución de ambos elencos ${ }^{9}$. Curiosamente este tipo de contratiempos económicos suelen suscitar la gestación de grandes proyectos artísticos y sociales, en los que el trabajo colaborativo se convierte en el pilar fundamental para levantar grandes ideas. El espíritu de Jorge Peña Hen fue pensar a largo plazo y, más que tratar de recuperar los recursos que se habían perdido, se propuso el objetivo de formar nuevos músicos en la zona. Esta labor se vería truncada en 1973 debido al comienzo de la dictadura militar de Augusto Pinochet y el asesinato del maestro Peña Hen en la llamada Caravana de la muerte.

El legado de Peña Hen ha sido reconocido como fundacional para la labor social de las orquestas infantiles y juveniles de toda Latinoamérica. De hecho, la Orquesta de las Américas (YOA) eligió a Chile como sede para su gira del 2012 con el fin de conmemorar el trabajo realizado por Peña Hen y su repercusión en otros países ${ }^{10}$. Fernando Rosas es la figura que retoma en Chile la formación de orquestas juveniles durante 1992, una vez superado lo que él mismo denominó como "el apagón cultural" 11 , haciendo alusión a los oscuros años que se vivieron durante la dictadura. Posteriormente, y gracias a la gestión de Rosas, nace la Fundación Nacional de Orquestas Juveniles e Infantiles de Chile bajo el gobierno de Ricardo Lagos Escobar en 2001. Se reinicia de esta forma una actividad que contempla hoy a más de 450 orquestas distribuidas en 221 comunas de Arica a Punta Arenas ${ }^{12}$.

No obstante, más allá de los importantes números que podemos apreciar desde la Fundación de Orquestas, me parece prudente rescatar lo que ocurre al interior de esos conjuntos. Al integrarme

3 Egaña del Sol 2007.

4 Fernández Calvo 2003.

5 Tunstall 2013.

6 Abreu, citado en Tunstall 2013:70.

7 De hecho existe una relación directa entre la obra de Jorge Peña Hen y el proyecto liderado por Abreu en Venezuela, ver Concha 2012.

8 Esta agrupación no debe confundirse con la Sociedad Bach fundada en 1917 que, bajo el liderazgo de Domingo Santa Cruz Wilson, impulsó la actividad artística y musical en Chile entre 1924 y 1932.

9 Castillo 2015.

10 Concha 2012.

11 Rosas 1997: 101.

12 Cifras obtenidas de Memoria FOJI 2017. 
a trabajar en la ópera La Malén, pude dimensionar la interesante actividad cultural que se vive en Panguipulli. El programa Vive la Música al que pertenece la Orquesta Sinfónica de la comuna, consta de cuatro etapas formativas: 1) Etapa de exploración; 2) Etapa de apresto; 3) Etapa básica musical; y 4) Etapa de nivelación. Estas diferentes fases funcionan en lo que ellos denominan Núcleos Educacionales, los que funcionan paralelamente en 22 establecimientos atendiendo a más de 1.100 niños y jóvenes ${ }^{13}$. Veo con alegría cómo este tipo de proyectos pone en práctica el sueño de Peña Hen e instala la música como una instancia de desarrollo comunitario. Detrás de esos niños hay también 1.100 familias que los acompañan en este camino, los ven practicando instrumentos que quizás eran desconocidos para ellos y también asisten por primera vez a un concierto o tienen los primeros acercamientos a este mundo musical.

\section{ÓPERA Y NIÑOS}

La idea de acercar el mundo de la ópera a los niños ha sido instalada en varios teatros que actualmente tienen, en sus temporadas, funciones de óperas célebres reducidas o adaptadas para un público infantil. Algunos ejemplos de ello son la Temporada del Pequeño Municipal en el Teatro Municipal de Santiago, el Colón para Chicos del Teatro Colón de Buenos Aires o el Pequeño Colón en Bogotá, Colombia. Bajo esta misma línea, en 2015 el Teatro Municipal de Santiago encargó al compositor chileno Sebastián Errázuriz Rodríguez la ópera infantil Papelucho, basada en el mítico personaje de Marcela Paz, la que fue un éxito total durante la Temporada del Pequeño Municipal. Sin embargo, todos estos proyectos dirigidos a niños han sido interpretados por músicos adultos y profesionales.

El formato de ópera infantil interpretada por niños no es habitual. La participación de niños en la ópera, en cambio, ha trascendido distintas épocas y estilos musicales. Ya célebres compositores habían creado roles que fueron interpretados inicialmente por niños, como es el caso de Los Tres Genios de La Flauta Mágica de Mozart. En música del siglo XX se encuentra el caso de la escena final de la ópera Wozzeck de Alban Berg, en la que el hijo de la protagonista canta “¡Hopp, hopp!” mientras juega con un caballito de madera, indiferente a la noticia de la muerte de su madre. La ópera Brundibár de Hans Krása escrita en 1938 fue concebida para ser cantada por niños, pero tocada por adultos. Esta ópera escrita inicialmente para un concurso se imbrica con una historia de triste desenlace. Luego de las representaciones que tuvo en 1943 al interior de un campo de concentración, sus protagonistas fueron trasladados hacia Auschwitz y otros destinos similares ${ }^{14}$.

Pareciera que las voces blancas han representado un timbre interesante para algunos compositores, lo que podemos apreciar en obras monumentales como la Sinfonía $n^{\circ} 3$ en re menor de Gustav Mahler o la Sinfonía Dante de Franz Liszt, en las que se incorporan coros de niños. Para mi proyecto composicional, más allá del uso de voces blancas como timbre, me interesaba hallar referentes que han encontrado en la ópera una experiencia educativa significativa para los niños. En 2006 la regisseur Miryam Singer llevó a cabo el proyecto Los Niños de Chile Cantan La Flauta Mágica de Mozart, el que recorrió varias ciudades de la Región de O’Higgins y de la Región Metropolitana de Chile interpretando una versión reducida de esa ópera con la participación de coros de cada una de las comunas en las que fue representada. La Cenicienta de Jorge Peña Hen es posiblemente uno de los referentes más importantes que reúne la conjunción ópera para niños-interpretada por niños. Esta ópera además fue parte del repertorio de varias de las giras nacionales e internacionales que Peña Hen y su orquesta realizaron durante la década de $1960^{15}$.

En relación con la ópera infantil interpretada por niños, si bien la obra comisionada ofrecía una interesante combinación de mundos sonoros; implicaba también tomar importantes decisiones acerca de cómo mezclar todos estos elementos. No debía olvidar que además de ser una obra para niños, esta sería interpretada también por niños y jóvenes tanto del coro como de la orquesta. Inicialmente, los únicos profesionales que consideraba el proyecto eran el grupo de solistas que obtuvieron los roles por concurso: Vanessa Rojas (Malén), Denise Torre (Machi y Pangui), Florencia Romero (Kalku) y María José Uribarri (Guerrero). A medida que avanzaba mi trabajo composicional, me encontré por ejemplo con el aria Nüküfkülen, la que corresponde al momento más oscuro de Malén. En esta aria,

13 Cifras obtenidas de Memoria 2018 Corporación de Adelanto Amigos de Panguipulli.

14 Rovit 2000.

15 Castillo 2015. 
nuestra protagonista se encuentra sola en el bosque e inicia su recorrido para romper el hechizo que ha convertido su cara en calavera. Era el momento preciso para componer un aria de mayor dificultad y virtuosismo vocal. Rodolfo Fischer me sugirió como referente sonoro una parte de la ópera Jenůfa de Leoš Janáček, en la que aparece un violín solista. Me gustó tanto la idea que decidí incorporar también un violín en escena a cargo de Carlos Romero, profesor de violín de la orquesta. Desde que fui invitado a participar en el proyecto me pareció muy interesante que se hubiera considerado la participación de solistas profesionales, ya que estos podrían servir como guía y referente para los niños. Relacioné esto de inmediato con algunas ideas del Sistema de Orquestas de Venezuela, el que promueve la interacción de músicos aprendices con otros más avanzados o bien profesionales ${ }^{16}$. Esta práctica de esfuerzo común que responde a dinámicas de identificación y trabajo en equipo se podía ver reflejada también en esa combinación de profesionales y estudiantes. Curiosamente el violinista Carlos Romero es venezolano.

\section{EXPLORANDO SONIDOS DEL BOSQUE}

Otro de los mundos sonoros que me interesaba explorar, para este encargo, era el de la música contemporánea. Estilísticamente tuve total libertad para utilizar el lenguaje musical que estimara conveniente. Por fortuna, tanto el maestro Fischer como la Corporación de Adelanto Amigos de Panguipulli confiaron totalmente en mi criterio, así que, con la composición de esta ópera, también pude incorporar la idea de acercar la música contemporánea a los niños. Un referente importante fue el proyecto Desde Fuera del Centro, liderado por Francisco Silva Cárdenas, compositor chileno, y Camila Roa, el que busca descentralizar el acceso a la música contemporánea. Para ello, sus creadores en 2013 y 2016 realizaron talleres y conciertos en la Región de Valparaíso dirigidos a alumnos y profesores de escuelas rurales. Existen dos documentales pertinentes al proyecto, en los que se puede apreciar la disposición de los niños para experimentar en torno al sonido y cómo este tipo de experiencias otorgan situaciones lúdicas que traen consigo aprendizajes significativos ${ }^{17}$. Curiosamente, a pesar de haber trabajado más de diez años en proyectos de orquestas, mi único acercamiento a la combinación orquesta infantil con música contemporánea se dio en 2016. Ese año la Fundación Toccata me encargó una obra breve para la Orquesta Juvenil de Rancagua, en la que pude incorporar algunos elementos de notación no convencional y uso de técnicas extendidas. Paradojas de la vida, ya que con la Orquesta de Paine podría haber estrenado más de alguna de mis obras.

Para la composición de La Malén, la ubicación geográfica de Panguipulli me ofrecía la oportunidad de realizar un interesante trabajo de experimentación en torno al paisaje sonoro del lugar. Murray Schafer subraya la importancia que tienen los sonidos del entorno sonoro inmediato, los que pueden constituir la base para un nuevo tipo de educación musical ${ }^{18}$. Basada en esta idea, la obra explora una gran cantidad de notación no convencional, uso de efectos y técnicas extendidas. Quería que, con esta obra, los niños pudieran conocer nuevas posibilidades sonoras en sus instrumentos. Creo firmemente que así debiesen ser los primeros acercamientos a un instrumento y propongo que una buena forma para los niños de experimentar y conocer su propio instrumento es mediante una búsqueda sonora relacionada a su propio entorno. Algunos autores proponen que las nuevas grafías de los siglos XX y XXI permiten un acercamiento a los instrumentos de manera más intuitiva, así como ocurre en la obra Játékok de György Kurtág, en la que se propone un acercamiento espontáneo al piano por medio del juego ${ }^{19}$.

Trabajar con el entorno sonoro implica agudizar la audición y promover la exploración. En la obertura de la ópera, por ejemplo, aparece un giro de tercera menor en la trompeta y los cornos con la simple y quizás ambigua indicación como trutrucas. Esta instrucción puesta a propósito en la partitura

16 Tunstall 2013.

17 Los documentales del proyecto Desde Fuera del Centro se encuentran disponibles en: www.youtube.com/watch?v=MEB1SGcgmsY\&fbclid=IwAR3kaEHuvwHBfn4NwLvcYS5vTL19UqS

04o3HcBiefaXIAULHpAKIGRs4Wp4 www.youtube.com/watch?v=h7hYmSeMmK4\&fbclid=IwAR3yhUJay1 mLDPC41pvJ0P2k7SPgb

Wp_BxjofTnbBaRIPdwwY9rtoEmPrlk

18 Schafer 1985.

19 Cavaye 1996. 
implica inevitablemente una audición avanzada que permita reconocer y reproducir cómo suena una trutruca. Para Schafer es importante aprender a escuchar y en sus textos ha propuesto una serie de simples ejercicios que, aplicados al aula, podrían contribuir a lo que él denomina limpieza de oídos ${ }^{20}$. Situaciones similares ocurren en otras partes de la obra en las que requiero, mediante ciertas grafías, imitar sonidos de pájaros. Cuando llegué a Panguipulli al primer ensayo con orquesta, la mayoría de los niños tocaban solo trinos en esa sección de la obra. Hice un pequeño ensayo parcial con la fila de las maderas y le encargué a cada músico encontrar tres sonidos propios de aves que conocieran. Les puse el ejemplo de las bandurrias que con su fuerte canto interrumpieron varios ensayos. Les di un par de minutos de práctica y exploración sonora individual. Pasado ese tiempo cada músico presentó sus tres sonidos y con alegría descubrí que eran muy pocos los que hacían solo trinos, la mayoría había encontrado nuevos sonidos y ya teníamos un verdadero bosque de pájaros para esa sección de la obra (Imagen 1).

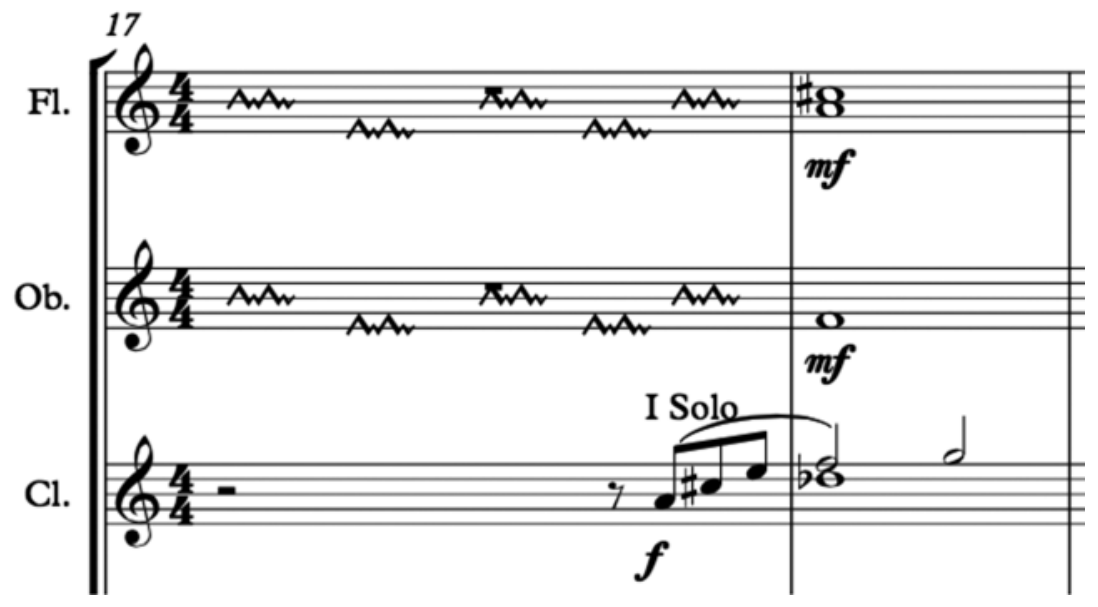

Imagen 1

Pasajes de la obertura donde las maderas deben imitar sonidos de pájaros

\section{LA MALÉN, UNA ÓPERA COMUNITARIA}

Así como la parte creativa de la ópera La Malén fue lograda solo gracias al trabajo mancomunado del equipo Castro-Fischer-Silva, el montaje de la obra significó el despliegue de un equipo humano que involucró literalmente a toda la comuna de Panguipulli. Por un lado, la parte artística "arriba de escena", donde podemos considerar el trabajo orquestal, coral y de danza liderado por el sólido equipo de profesores de la Casona Cultural de Panguipulli. Por otro lado, en todo lo que ocurre "detrás de escena" es donde me quiero detener un momento para contar por qué La Malén es realmente una ópera comunitaria.

En este proyecto, la ópera se convirtió en un espacio en el que la gente de Panguipulli se pudo encontrar activamente, aunando voluntades y ayudando con valiosas horas de trabajo colaborativo. Bajo este espíritu se hizo un llamado a la comunidad, conformándose así un grupo de padres, madres, abuelos y vecinos del lugar que le dio vida al vestuario diseñado por Marianela Caamaño (Imágenes 2 y 3 ). La escenografía, por su parte, también fue construida bajo esta misma premisa de trabajo colaborativo, participando en ello estudiantes de construcción del Instituto Técnico IPG de Panguipulli. Además, el trabajo colaborativo no se detiene en estos dos casos, ya que en cada momento veía a apoderados preocupados de entregar colaciones, controlar accesos, entregando programas, etcétera.

20 Schafer 1982. 


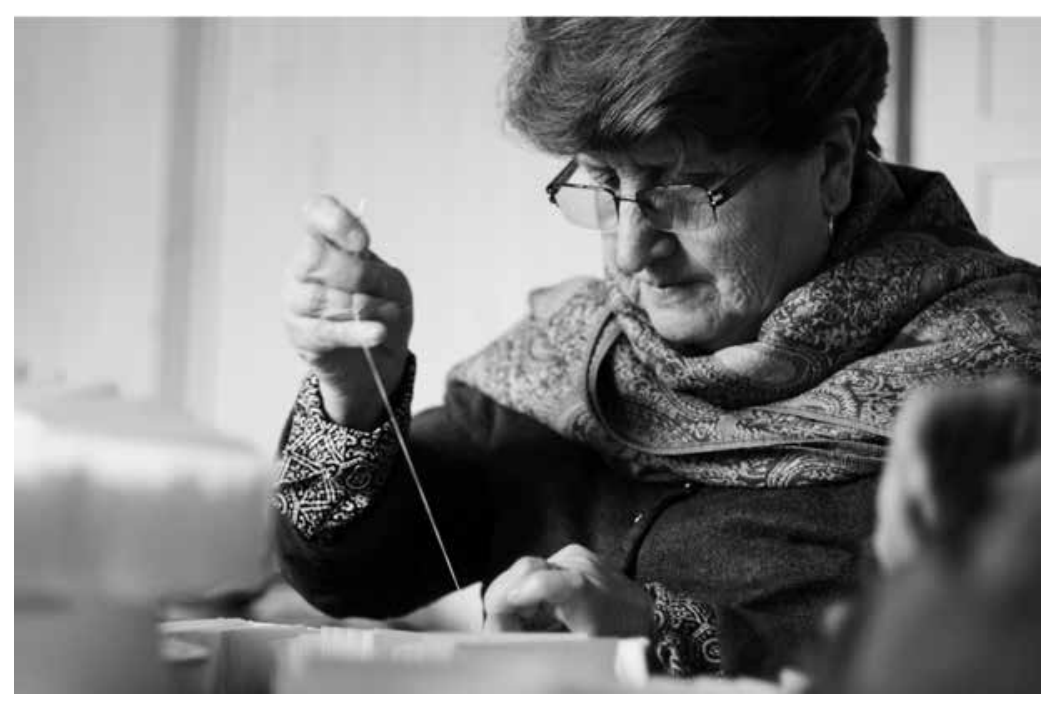

Imagen 2

Voluntaria en taller de vestuario Foto: Alejandro Hidalgo

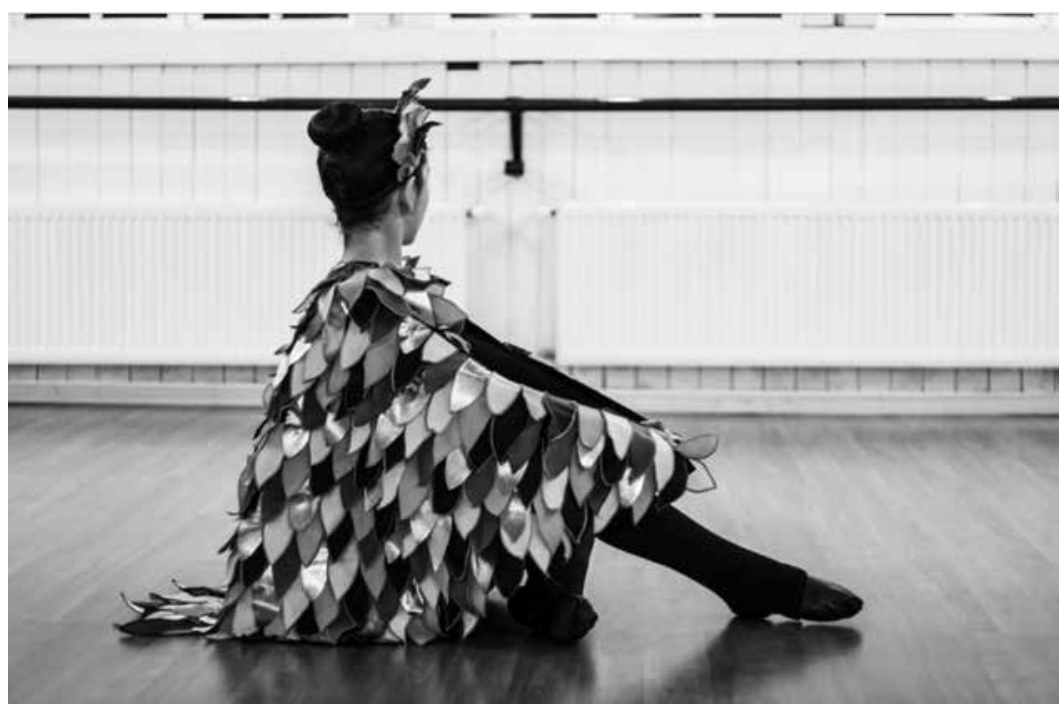

Imagen 3

Bailarina en prueba de vestuario elaborado por voluntarios Foto: Alejandro Hidalgo

Sumado a esto, el proyecto Cenicienta, Magia y Leyenda requería de un hilo conductor que permitiera unir los estilos musicales tan disímiles de la obra de Pedro Humberto Allende y de la mía. Si bien ambas narraciones tienen la historia de Cenicienta como punto de conexión, había 
que buscar la forma de unirlas. Felipe Castro, con su innata creatividad, propuso a dos personajes externos a ambas historias: una niña y su papai ${ }^{21}$. Del relato de cada una de ellas es que nace cada historia. La primera (de Allende), desde el relato de princesas y castillos de la niña; la segunda (de Silva), desde el relato de papai, quien le cuenta a su nieta acerca de las historias locales, en las que también hay princesas. El rol de papai sería interpretado inicialmente por una actriz, pero este fue asumido finalmente por Elena Catripán Huentequeo, residente del sector de Coihueco e integrante de diferentes organizaciones comunitarias. Unos días antes del estreno de la ópera, Elena invitó a todo el elenco a compartir en su $r u k a^{22}$. Ahí nos contó que se decidió a ser parte del equipo al enterarse de que participarían tantos niños. Para ella, era una excelente manera de mostrar su cultura, nos dijo emocionada al borde del fogón.

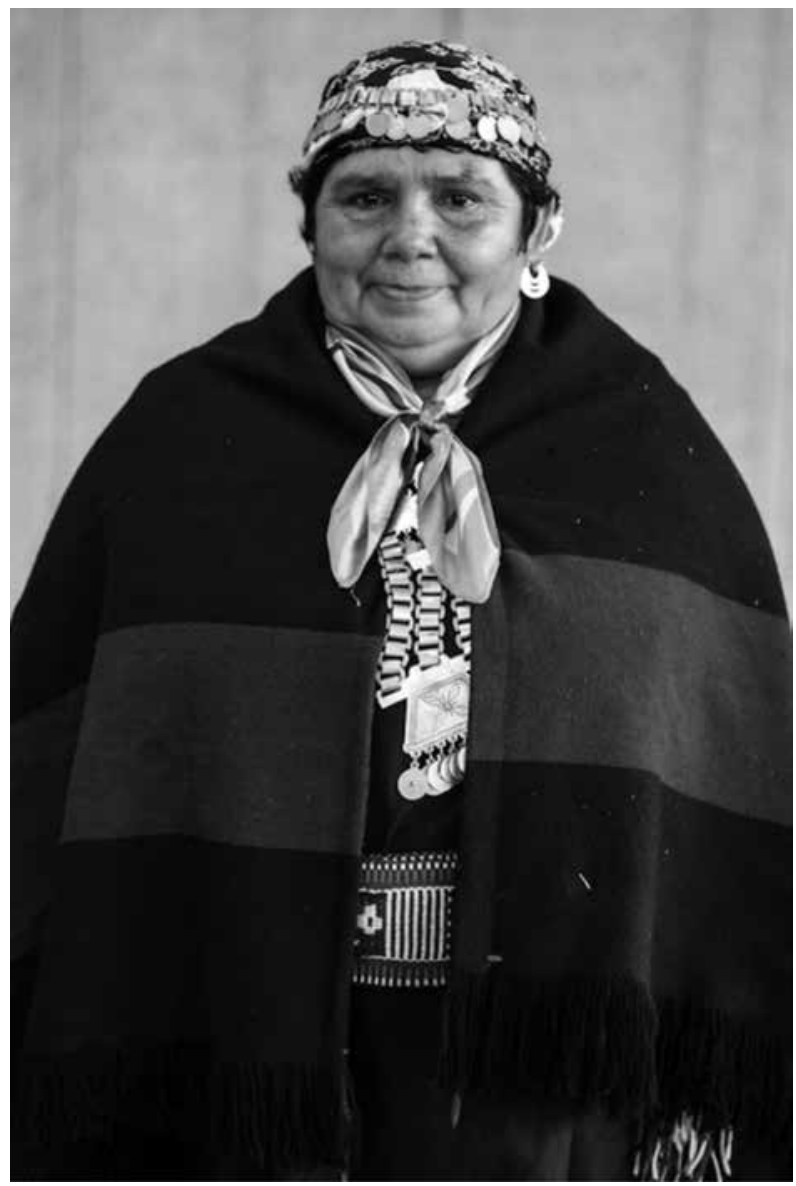

Imagen 4

Papai

Elena Catripán Huentequeo

Foto: Alejandro Hidalgo

21 Papai significa abuelita en mapudungún, idioma de la cultura mapuche.

22 Ruka o ruca es el nombre que se da a la vivienda tradicional mapuche (N. del E.). 
No puedo más que recordar con emoción cómo tanta gente trabajó por hacer sonar mi música. Es difícil asumir la autoría de una obra en la que colaboraron tantas manos y tantas voces. Meses y meses de trabajo que invirtieron tantas personas anónimas me hacen reflexionar en torno al poder de la música como elemento unificador de comunidades. Aquí no existieron banderas políticas, simplemente un proyecto comunitario al que tuve la suerte de ser invitado.

La ópera resultó todo un éxito, sumando con sus funciones en Panguipulli y el Teatro Municipal de Las Condes a más de 5.000 espectadores. Pero más allá de los números, me reconforta saber que este proyecto no quedará como un bonito recuerdo, sino que se proyecta en el tiempo. He sido invitado recientemente por la Casona Cultural de Panguipulli para realizar durante tres días un taller de creación y exploración sonora con los niños y niñas de la orquesta. Además de ello, también me fue comisionada la realización de una suite instrumental con la música de la ópera, la que será interpretada durante una gira por el sur de Chile y Argentina en 2020. Al parecer, el canto de Malén seguirá sonando por un tiempo entre estos bosques y montañas.

\section{BIBLIOGRAFÍA}

Castillo Didier, Miguel

2015 Jorge Peña Hen (1928-1973): músico, maestro y mártir. Santiago de Chile: LOM.

Cavaye, Ronald

1996 "Játékok los juegos de György Kurtág”, Quodlibet: revista de especialización musical, II/4, pp. 73-89.

Concha Molinari, Olivia

2012 "El legado de Jorge Peña Hen: las orquestas sinfónicas infantiles y juveniles en Chile y en América Latina”, Revista Musical Chilena, LXVI/218, pp. 60-65.

Corporación de Adelanto Amigos de Panguipulli

2018 Memoria 2018. Panguipulli: Corporación de Adelanto Amigos de Panguipulli.

Egaña del Sol, PABlo

2007 "Orquestas infantiles y juveniles: evaluación de impacto en rendimiento escolar", en Encuentro Anual de la Sociedad de Economía de Chile. Reñaca. Disponible en: www.sechi.cl.

Fernández Calvo, Diana

2003 La integración social de los niños y jóvenes pobres, a través de la música: proyectos de orquestas juveniles en América Latina y en la Argentina. Disponible en: www.especialmentemusica.com.ar/ descargas/articulos_varios/articulo_varios_13.pdf

Fundación de Orquestas Juveniles e Infantiles de Chile

2017 Memoria Institucional 2017. Gestión 2014-2017. Santiago de Chile: FOJI.

Rosas, FERnANDo

1997 "Mi experiencia musical en el Chile de hoy", Revista Musical Chilena, LI/188 (julio-diciembre), pp. 100-102.

Rovit, ReBECCA

2000 "The 'Brundibár' Project: Memorializing Theresienstadt Children's Opera”, PAJ: a Journal of Perfomance and Art, XXII/65, pp. 111-122.

SCHAFER, Murray

1982 Limpieza de oídos: Notas para un curso de música experimental. Buenos Aires: Ricordi.

1985 El nuevo paisaje sonoro: un manual para el maestro de música moderno. Buenos Aires: Ricordi.

Tunstall, Tricia

2013 "Another Perspective. El Sistema-A Perspective for North American Music Educators", Music Educators Journal, C/1, pp. 69-71. 